\title{
Morte, Tradição e Modernidade
}

\author{
Apresentação
}

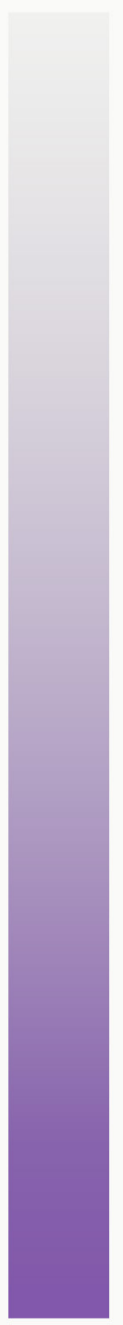

radição e contemporaneidade têm, via de regra, sido discutidas e refletidas desde suas posições dialéticas e/ou dialógicas, sendo colocadas muitas vezes como conceitos antagônicos, ainda que tenhamos cada vez mais a clareza de que as definições são flexíveis e jamais excludentes. No entanto, quando os relacionamos à morte e ao morrer, imprimimos uma nova dinâmica a estas reflexões e não raras vezes somos surpreendidos pelas posições possíveis a partir destas junções, tal como apontam os trabalhos de Davies (1997), Howarth (2007), Kellehear (2007), entre outros em distintas perspectivas.

Esta suposta oposição entre "tradição" e "modernidade" (ou contemporaneidade) é em grande medida consequência da gênese do pensamento relacional, que resulta em métodos comparativos de análise, estando a "modernidade", como fato e como teoria (assim como a "tradição" e toda a criação envolta nela) muitas vezes sujeita à periodização, numa tentativa de datá-la, impondo, assim, limites temporais (e algumas vezes geográficos) para estas definições. Não é esta, entretanto, a postura que vem sendo partilhada por grande parte dos historiadores, antropólogos e sociólogos, como bem apontam Smart (1990), Appadurai (1996) e Habermas (2000) ao refletirem acerca das adaptações de ideias e símbolos dos circuitos globais de produção e conhecimento, os quais são resinificados, reapropriados e hibridizados num processo que

* Pós-Doutora em Antropologia pelo Centro em Rede de Investigação em Antropologia, da Universidade Nova de Lisboa, Portugal. Pós Doutora em Antropologia Social pelo Instituto de Ciências Sociais (ICS), da Universidade de Lisboa, Portugal. Doutora em Linguistica Africana pela Universidade de São Paulo (USP), Brasil. CV: <http://lattes. cnpq.br/6557567870604974>

** Doctor en Historia (Etnohistoria Andina/Novohispana, siglos XVI y XVII), por la Universidad de Chile (2016). Antropólogo Social. Asesor externo del Ministerio de Cultura - DDC, Cusco y asesor externo del Centro Bartolomé de Las Casas, CBC. CV: <https://unsaac.academia.edu/AlejandroHerreraVillagra/CurriculumVitae>. 
pode gerar múltiplas e alternativas formas de fazer (ver Comaroff e Comaroff, 1993; Miller, 1995; Englund e Leach, 2000; Inda e Rosaldo, 2001). Os debates atuais centralizam-se muito mais no modo como a homogeneização e a diferenciação ocorrem ao mesmo tempo e como a continuidade e a mudança devem ser percebidas e analisadas em sua complexidade (Wilk, 1995; Sahlins, 1999; Robbins, 2004).

A proposta deste dossiê é trazer mais uma contribuição sobre os modos como as diferentes sociedades têm entendido e vivido o fenômeno da morte e o que esteja a ela relacionado ritos, cuidados que a antecedem, cuidados com o corpo e com a alma/espírito/força vital etc., com as memórias -, indo além da perspectiva histórica e dialogando também desde o ponto de vista político e/ou antropológico. Busca evidenciar não apenas os amálgamas epistemológicos mas também valorizar produções em que os vínculos entre conceitos norteadores deste dossiê estejam latentes.

Nessa perspectiva, pudemos reunir textos em que estas imbricações e rupturas com o dualismo fácil estão nítidos, pois o conjunto de seis artigos que compõem este dossiê evidenciam as escolhas dos autores aqui presentes, seja porque tratamos aqui da morte e do morrer maiormente no contexto latino-americano (local por excelência onde as combinações - híbridas - de tradição e modernidade são latentes sem que uma desloque a outra), seja porque as próprias ferramentas analíticas para observação dos fenômenos apresentam porosidade suficiente para que haja diálogo entre as disciplinas.

Portanto, se há de fato uma narrativa espacial e temporal (King, 1995) na qual a modernidade e a tradição parecem ter sua origem (o que faria com que a tradição pudesse atuar como um "contexto" para a modernidade), podemos vislumbrá-la nos textos de Ana Stela Cunha, Trocas e reconfigurações religiosas no Baixo Congo: poder e morte entre os chineses e os bacongos e de Renata Rezende Ribeiro, Redes de memória e de comemoração: a ressignificação da morte no contexto de novas mídias. Neles, as autoras trazem dados etnográficos de naturezas distintas (uma, do Baixo Congo, no continente africano, e a outra, das redes sociais, um "espaço em aberto", ou o "não espaço") e nos mostram de que modo a contemporaneidade permeia práticas tidas como "tradicionais".

O artigo de Ana Stela Cunha nos traz algumas das mudanças que vem ocorrendo em relação à morte e ao morrer num grupo étnico no Congo, ao apresentar reflexões acerca dos recentes contatos religiosos entre chineses ali residentes (zona do Baixo Congo) e membros de uma "sociedade secreta" entre os maniangas, capazes de reavivar mortos. Atualmente, devido aos interesses de ambos grupos, o reavivamento de mortos vem sendo acompanhado pelo suposto tráfico de órgãos empreendido pela comunidade chinesa; o que tem gerado na comunidade local o medo em relação ao tratamento que será dado aos corpos dos mortos (levando inclusive a que as famílias passem a adotar a desintegração dos mesmos, com o uso de ácido, evitando assim possíveis usos, considerados por eles indevidos, dos órgãos de seus familiares). O trabalho é resultado de uma extensa etnografia feita na República Democrática do Congo, mas também em Portugal, com os bacongos imigrantes. Como num caderno de campo, a autora vai tecendo considerações a respeito dos relatos e uma possível reconfiguração religiosa a partir destes encontros, num diálogo constante com a literatura 
pertinente, evidenciando esta delicada rede em que ritos tradicionais vão se redesenhando a partir de interesses religiosos e econômicos, onde tradição e "modernidade" caminham lado a lado.

Se no Congo o encontro dos chineses com uma sociedade secreta tem gerado novas configurações religiosas, inclusive com novas práticas funerárias e cuidados com os corpos, na etnografia seguinte - ou "netnografia", como propõem estudos mais recentes -, vemos igualmente de que modo as tradições (como as ligadas aos ritos fúnebres e ao luto) assumem novas faces a partir da "virtualidade" das redes sociais. O texto de Renata Rezende Ribeiro é sobre a ressignificação da morte na contemporaneidade midiática, em que a imbricação entre corpo, comunicação e tecnologias digitais de informação articula novas leituras sobre a temática da morte e do morrer. Ao realizar uma reflexão sobre os usos da memória e das comemorações nas redes sociais digitais, especialmente no Facebook - que, em 2015, criou a ferramenta "contato herdeiro", promovendo de forma institucional a celebração dos mortos na rede - e também a partir de pesquisa exploratória nas redes sociais, o artigo nos mostra de que modo a ambiência digital opera como uma espécie de "guardiã da memória", na medida em que celebra e atualiza as narrativas dos e sobre os mortos. Assim, neste paradoxal compromisso da antropologia com o relativismo cultural (particularismo) e a igualdade cultural (universalismo), as autoras evidenciam o fato de que somos todos coetâneos, "somos todos modernos" - ou que nunca fomos modernos - para adaptar a frase de Latour (1993), pois dizer que todos somos igualmente modernos não é o mesmo que dizer que a modernidade ocidental realizou uma varredura completa. É, em vez disso, uma maneira de contestar a suposição eurocêntrica de que alguns estão "à frente" dos outros em uma presumida escala de progresso.

Ao abordar a morte e o morrer no século XVIII, ao norte de Portugal, o texto de Norberto Tiago Gonçalves Ferraz, apresenta-nos outra forma de dialogar neste mesmo sentido. Intitulado O Purgatório e a salvação da alma nos Setecentos, o autor dá-nos a conhecer os mecanismos espirituais utilizados pelos bracarenses para obterem a salvação da alma no além-túmulo, evitando a condenação eterna do Inferno e o rápido resgate dos castigos do Purgatório. É um texto pautado num trabalho documental minucioso das confrarias das Almas de Braga (fazendo uso também de 250 testamentos setecentistas), conduzindo-nos ao entendimento dos modos como estas associações religiosas católicas celebravam missas pelas almas de todos sem distinção, apontando os serviços espirituais que os fiéis determinavam para serem celebrados durante o período de velório e após o enterro. É, pois, uma outra forma de refletir acerca desta coetaneidade dentro das tradições, criando diálogos plurais através das distintas formas de fazer a memória e seus muitos modos de operar e atuar, já que o espacial e o temporal na modernidade não são apenas o "depois" da tradição, são antes o "além" da localidade e atuam como o contexto mais amplo.

Esta discussão se estende pelos textos de Adriane Piovezan, A morte e o morrer na guerra: os enterramentos dos soldados brasileiros na Segunda Guerra Mundial, no qual analisa as práticas funerárias, os rituais e as devoções dos soldados brasileiros mortos na Segunda Guerra Mundial (1939-1945). Vê-se aqui, sobretudo, o cuidado com o corpo, mas também a preocupação com a imagem social e a sua representatividade, a partir das fontes geradas 
pelo Pelotão de Sepultamento da FEB (Força Expedicionária Brasileira), responsável pelo recolhimento, identificação e enterramento dos soldados. Aspecto que revela que a relação da sociedade brasileira com a morte nesse período conheceu os conflitos, mas também a cooperação entre as instituições religiosas e militares e destas com a população. $O$ que se discute, aqui, são novas formas de se pensar a morte num contexto social específico (o da guerra) e como eram tratados não apenas os corpos mas sobretudo as representações e as memórias, já que com a entrada do Brasil no conflito mundial em 1942 e o envio da FEB para o teatro de operações na Itália em 1944, ocorreu a criação de um Pelotão de Sepultamento (PS), cuja intenção era a da preparação individual do soldado para a probabilidade de sua própria morte, bem como os procedimentos institucionais destinados ao tratamento dos mortos.

Aliás, o tema da memória em nosso contexto ocidental/latino americano parece ser crucial, se pensamos em uma análise cultural da morte nas sociedades modernas ou em grandes cidades que controlam nossos países. Guerras, ditaduras, conflitos internos de todos os tipos, foram formatados com a história política ou apoio ideológico por parte dos governos que, via de regra, ocultam a memória e têm distorcido os processos democráticos após crises que envolveram altos custos sociais e humanos. O que antigamente era lúcida e corajosamente abordado pela literatura, pelo cinema e pela poesia, hoje também é validado pelas diferentes áreas do conhecimento.

O trabalho de Olmos e Keiholz-Rühle (2009), por exemplo, nos traz a experiência política e ideológica dos processos coletivos na Espanha e na Alemanha, após a ditadura de Franco e do regime nazista. Sem dúvida, a morte está na agenda dos países que experimentaram eventos traumáticos com elevado custo social em vidas humanas. Na América Latina, países como Chile, Peru e Argentina continuam hoje experimentando tensões sociais devido a casos de Direitos Humanos (DD. HH.) e presos desaparecidos, cuja forma jurídica é o "seqüestro permanente", que nos confronta com problemas de memória que não podem ser analisados apenas à luz do relativismo teórico ou ideológico, demandando um trabalho conjuntural ligado a aspectos jurídicos e políticos. Claro está que a morte e o morrer em ambientes mais específicos também podem ser analisados a partir de referenciais teóricos análogos envolvendo figuras ausentes e/ou comunitárias da memória social. A análise da memória, desde Maurice Halbwachs (2004 [1968]) a Paul Ricoeur (2008 [2000]), dentre outros, nos mostra que o coletivo, o político e o histórico também são a herança deixada pelos mortos, (re)criada e transformada, pelos vivos que conduzem suas agendas atuando na sociedade a partir de seus próprios pensamentos e objetivos específicos, mas igualmente (re)elaborando de diversas formas as tradições dos antepassados.

Esta relação permeada pela memória dos antepassados perpassa todo o texto de Alejandro Herrera Villagra, Funebria Andina. Las informaciones de don Felipe Guamán Poma de Ayala. Virreinato del Perú, siglos XVI y XVII, que tem como espaço geográfico a zona andina. Sua análise traz à discussão as informações históricas do referido "Intelectual Indígena", na obra Nueva corónica y buen gobierno (ca. 1615), com enfoque específico sobre os costumes fúnebres e a ideia de morte entre os diferentes grupos que habitavam a região antes da conquista e dominação hispânica e após a chegada do Cristianismo na área. São informações preciosas 
não apenas do ponto de vista histórico, uma vez que nos permitem distinguir diferentes tradições em torno da morte nos Andes pré-colonial (os incas, os "malkus qollas", os "yungas" da costa e os "chunchus" da floresta), mas também porque don Felipe Guamán Poma de Ayala travou contato com formas anteriores ao cristianismo de preparo para a morte, num período em que tais costumes vinham sendo sistematicamente proscritos pelo poder hispânico (desde 1570 até finais do século XVII). O autor nos traz então uma perspectiva étnico-histórica que em muito contribui para uma compreensão alargada sobre a morte neste contexto, cujas discussões recaem igualmente sobre a natureza mutuamente constitutiva da modernidade e da colonialidade (um termo que inclui, mas vai além do simples colonialismo). O texto evidencia o quanto a "modernidade" ocidental se baseava na dominação do não-ocidente, assinalando uma "fronteira" (Mignolo 2000) que acabou por dar origem a contestações éticas do discurso eurocêntrico dominante.

Este discurso contestatório evidencia-se, por fim, no texto La representación de la muerte en narraciones autorreferenciales fotográficas de enfermedad contemporáneas, de Rebeca Pardo, que sobretudo por sua forma epistemológica nos traz reflexões de certo modo metalinguísticas, abordando as numerosas "narrações visuais" auto referenciais das enfermidades terminais ou degenerativas que culminam com a morte. O texto aborda, dentro de um contexto "doméstico", a representação fotográfica da morte em situações de enfermidades como o câncer, o HIV (AIDS) ou as demências geriátricas. A autora preocupou-se em comparar as distintas enfermidades e os modos como o passamento é então representado, abordando este tipo de representação visual com uma análise que tem em conta a possibilidade de um luto antecipado frente a iminência da morte real do paciente.

Confrontando textos e ideias, datas e espaços, apresentamos aqui uma pequena amostra daquilo que vem sendo produzido sobre o tema da morte e do morrer tendo como perspectivas a tradição e a contemporaneidade, cientes de que ser novo não é o mesmo que ser moderno: coisas novas emergem continuamente, mas nem todas são rotuladas como "modernas". Vários estudiosos, de Edward Said (2014 [1978]) a Mignolo (2000) e Moreiras (2001), já apontaram para o fato de que as práticas de conhecimento acadêmico são, elas próprias, exemplos importantes de como as escalas e teleologias são construídas de modo a criar entidades e colocá-las em determinadas relações de poder (Castro-Gómez, 1998; Mignolo 2000; Moreiras, 2001). Como já bem argumentou García Canclini (1995, p. 141), "Toda cultura é o resultado de uma seleção e de uma combinação - constantemente renovada - de suas fontes. Em outras palavras, é um produto de uma encenação". Tal é a importância dos textos aqui reunidos.

\section{Referências Bibliográficas}

APPADURAI, Arjun. Modernity at large: Cultural dimensions of globalization. University of Minesotta Press, 1996. 237p.

CASTRO-GÓMEZ, Santiago. Latinoamericanismo, modernidad, globalización: prolegómenos 
a una crítica poscolonial de la razón. In: Santiago Castro-Gómez; Eduardo Mendieta (eds.). Teorías sin disciplina: latinoamericanismo, poscolonialidad y globalización en debate. México: Miguel Ángel Porrúa, p. 169-2015, 1998.

COMAROFF, Jean; COMAROFF, John L. (eds.). Modernity and Its Malcontents: Ritual and Power in Postcolonial Africa. Chicago: University of Chicago Press, 1993. 233p.

DUSSEL, Enrique. Eurocentrism and Modernity. In: BEVERLEY, John; OVIEDO, José; and ARONNA, Michael (eds.). The Postmodernism Debate in Latin America. Durham: Duke University Press, p. 65-76, 1995.

ENGLUND, Harri; LEACH, James. Ethnography and the Meta-Narratives of Modernity. Current Anthropology, 41, (2), p. 225-48, 2000.

GARCÍA CANCLINI, Néstor. Hybrid Cultures: Strategies for Entering and Leaving Modernity. Minneapolis: University of Minnesota Press, 1995. 344p.

HABERMAS, Jurgen. O discurso filosófico da modernidade. São Paulo: Martins Fontes, 2000. $540 \mathrm{p}$.

HALBWACHS, Maurice. La memoria colectiva. Zaragoza: Prensas Universitarias de Zaragoza, 2004 [1968]. 192p.

KELLEHEAR, Allan. Dying as a social relationship: A sociological review of debates on the determination of death. Social Science \& Medicine, 66, p. 1533-1544, 2007.

KING, Anthony D. The Times and Spaces of Modernity (or Who Needs Postmodernism?). In: FEATHERSTONE, Mike; LASH, Scott; ROBERTSON, Roland (eds.). Global Modernities. London: Sage, p. 109-123, 1995.

MIGNOLO, Walter. Local Histories/Global Designs: Coloniality, Subaltern Knowledges, and Border Thinking. Princeton: Princeton University Press, 2000. 371p.

MOREIRAS, Alberto. The Exhaustion of Difference: The Politics of Latin American Cultural Studies. Durham: Duke University Press, 2001. 350p.

OLMOS, Ignacio; KEIHOLZ-RUHLE, Nikky (Eds.). La cultura de la memoria. La memoria histórica en España y Alemania. Madrid: Iberoamericana-Vervuert, 2009. 205p.

RICOEUR, Paul. La memoria, la historia, el olvido. México: FCE, 2008 [2000]. 673p.

ROBBINS, Joel. The Globalization of Pentecostal and Charismatic Christianity. Annual Review of Anthropology, 33, p. 117-43, 2004.

ROSALDO, Renato. Utter Savages of Scientific Value. In: LEACOCK, Eleanor; LEE, Richard (eds.). Politics and History in Band Societies. Cambridge: Cambridge University Press, p. 309-325, 1982.

SAID, Edward W. Orientalismo. Santiago de Chile: DeBolsillo, 2014 [1978]. 510p. 